\title{
METODE PSEUDO ARC-LENGTH DAN PENERAPANNYA PADA PENYELESAIAN SISTEM PERSAMAAN NONLINIER TERPARAMETERISASI
}

\author{
RAHIMA SYAFITRI \\ Program Studi Matematika, \\ Fakultas Matematika dan Ilmu Pengetahuan Alam, Universitas Andalas, \\ Kampus UNAND Limau Manis Padang, Indonesia, \\ email : rahimasyafitri20@gmail.com
}

\begin{abstract}
Abstrak. Pada makalah ini dibahas tentang penurunan metode pseudo arc-length dalam menyelesaikan sistem persamaan nonlinier terparameterisasi dimana kurva solusinya memiliki titik balik. Ide dari metode ini adalah menambahkan persamaan bidang yang tegak lurus terhadap vektor singgung kurva pada sistem asal, sehingga diperoleh sistem diperluas yang selanjutnya diselesaikan dengan menggunakan metode Newton-Raphson. Metode pseudo arc-length ini kemudian diimplementasikan dalam pemrograman Matlab dengan mengambil contoh kasus pada penyelesaian persamaan Bratu diskrit.
\end{abstract}

Kata Kunci: Metode pseudo arc-length, persamaan nonlinier terparameterisasi, metode Newton-Raphson, turunan parsial, vektor singgung

\section{Pendahuluan}

Pandang persamaan

$$
f(x)=0
$$

dimana $f: \mathbb{R} \longrightarrow \mathbb{R}$ adalah fungsi kontinu dan terdiferensialkan, sedangkan $x \in$ $\mathbb{R}$ merupakan solusi yang ingin dicari. Untuk menentukan solusi tersebut secara numerik, dapat dilakukan dengan beberapa metode, salah satunya adalah metode Newton-Raphson [3].

Selanjutnya pandang persamaan

$$
f(x, \lambda)=0,
$$

dimana $\lambda$ adalah suatu parameter yang bernilai riil. Persamaan (1.2) disebut juga persamaan terparameterisasi. Metode perhitungan numerik untuk memperoleh kurva solusi dari persamaan (1.2) dapat juga dilakukan dengan menggunakan metode Newton-Raphson.

Meskipun demikian, metode ini tidak dapat menentukan nilai solusi $(x, \lambda)$ pada persamaan nonlinier yang kurva solusinya memiliki titik balik dalam $x$. Salah satu metode alternatif untuk mengatasi hal tersebut adalah dengan menggunakan metode pseudo arc-length. Metode ini dikembangkan pertama kali oleh Edward Riks dan Gerald Wempner pada akhir tahun 1960-an dan dipopulerkan oleh H.B. Keller pada akhir tahun 1970-an [5]. 
Pada metode ini, $x$ dan $\lambda$ diparameterisasi dalam variabel baru, misalkan $s$, kemudian $x(s)$ dan $\lambda(s)$ diselesaikan secara simultan untuk setiap $s$. Karena hanya ada satu persamaan, yaitu (1.2), maka perlu ada satu persamaan tambahan agar solusi $x$ dan $\lambda$ dapat diperoleh. Pada metode pseudo arc-length, persamaan tambahan tersebut adalah persamaan garis yang tegak lurus terhadap vektor singgung kurva. Dengan demikian titik-titik solusi dapat diperoleh meskipun setelah melewati titik balik.

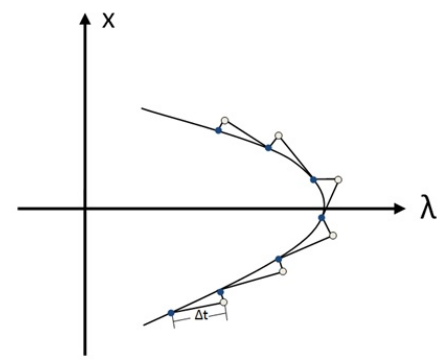

Gambar 1. Ilustrasi kurva metode pseudo arc-length

Dalam artikel ini akan dibahas metode pseudo arc-length pada penyelesaian sistem $n$ persamaan nonlinier terparameterisasi, dengan mengeksplorasi kembali pembahasan pada referensi [3].

\section{Beberapa Konsep}

\subsection{Rank dan Nulitas}

Definisi 2.1. [1] Dimensi dari ruang baris dan ruang kolom dari suatu matriks $A$ disebut rank dari $A$ dan dinotasikan dengan $\operatorname{rank}(A)$. Dimensi ruang null dari $A$ disebut sebagai nulitas dari $A$ dinotasikan dengan null $(A)$.

Teorema 2.2. [1] Jika A adalah matriks dengan n kolom, maka

$$
\operatorname{rank}(A)+\operatorname{null}(A)=n
$$

Teorema 2.3. [4] Jika $A$ matriks nonsingular $n \times n$ dan $\mathbf{b}$ vektor kolom $n \times 1$ sedemikian sehingga $\operatorname{rank}([A \mid \mathbf{b}])=n$, maka $\operatorname{null}([A \mid \mathbf{b}])=1$.

Teorema 2.4. [4] Misalkan A matriks nonsingular $n \times n$ dan $\mathbf{b}$ vektor kolom $n \times 1$ sedemikian sehingga $\operatorname{rank}([A \mid \mathbf{b}])=n$. Jika $[\mathbf{p} q]^{T} \in \operatorname{ker}([A \mid \mathbf{b}])$, maka matriks

$$
M=\left[\begin{array}{cc}
A & \mathbf{b} \\
\mathbf{p}^{T} & q
\end{array}\right]
$$

adalah matriks nonsingular. 


\subsection{Persamaan Bidang}

Misalkan $\mathbf{n}=\left(u_{1}, u_{2}, \cdots, u_{n}\right)$ suatu vektor tak nol dan $P_{0}\left(x_{1}^{(0)}, x_{2}^{(0)}, \cdots, x_{n}^{(0)}\right)$ suatu titik tetap. Himpunan dari titik-titik $P\left(x_{1}, x_{2}, \cdots, x_{n}\right)$ yang memenuhi $\overrightarrow{P_{0} P} \cdot \mathbf{n}=0$ adalah bidang yang melewati $P_{0}$ dan tegak lurus terhadap $\mathbf{n}$. Untuk mendapatkan persamaan kartesius dari bidang, tulis vektor $\overrightarrow{P_{0} P}$ dalam bentuk

$$
\overrightarrow{P_{0} P}=\left(x_{1}-x_{1}^{(0)}, x_{2}-x_{2}^{(0)}, \cdots, x_{n}-x_{n}^{(0)}\right) .
$$

Dengan demikian $\overrightarrow{P_{0} P} \cdot \mathbf{n}=0$ ekuivalen dengan

$$
u_{1}\left(x_{1}-x_{1}^{(0)}\right)+u_{2}\left(x_{2}-x_{2}^{(0)}\right)+\cdots+u_{n}\left(x_{n}-x_{n}^{(0)}\right)=0 .
$$

Persamaan (2.3) disebut bentuk umum dari persamaan bidang.

\subsection{Vektor Singgung}

Turunan fungsi vektor $\mathbf{r}(t)$ terhadap $t$ (suatu parameter), yang dinyatakan oleh $\mathbf{r}^{\prime}(t)$, didefinisikan sebagai

$$
\mathbf{r}^{\prime}(t)=\lim _{h \rightarrow 0} \frac{\mathbf{r}(t+h)-\mathbf{r}(t)}{h}
$$

asalkan limitnya ada. Dalam hal ini, vektor singgung satuan diberikan oleh

$$
\mathbf{T}(t)=\frac{\mathbf{r}^{\prime}(t)}{\left\|\mathbf{r}^{\prime}(t)\right\|} .
$$

\subsection{Metode Newton-Raphson}

Secara umum, metode iterasi Newton-Raphson pada sistem $n$ dimensi dapat dilakukan dengan algoritma berikut:

Misalkan pada saat iterasi ke- $k$ nilai $\mathbf{p}_{k}=\left(p_{1}^{(k)}, p_{2}^{(k)}, \cdots, p_{n}^{(k)}\right)$ telah diperoleh.

(1) Hitung fungsi

$$
\mathbf{f}\left(\mathbf{p}_{k}\right)=\left[\begin{array}{c}
f_{1}\left(p_{1}^{(k)}, p_{2}^{(k)}, \cdots, p_{n}^{(k)}\right) \\
f_{2}\left(p_{1}^{(k)}, p_{2}^{(k)}, \cdots, p_{n}^{(k)}\right) \\
\vdots \\
f_{n}\left(p_{1}^{(k)}, p_{2}^{(k)}, \cdots, p_{n}^{(k)}\right)
\end{array}\right]
$$

(2) Hitung matriks Jacobian

$$
\mathbf{J}\left(\mathbf{P}_{k}\right)=\left[\begin{array}{cccc}
\frac{\partial f_{1}}{\partial x_{1}}\left(\mathbf{p}_{k}\right) & \frac{\partial f_{1}}{\partial x_{2}}\left(\mathbf{p}_{k}\right) & \cdots & \frac{\partial f_{1}}{\partial x_{n}}\left(\mathbf{p}_{k}\right) \\
\frac{\partial f_{2}}{\partial x_{1}}\left(\mathbf{p}_{k}\right) & \frac{\partial f_{2}}{\partial x_{2}}\left(\mathbf{p}_{k}\right) & \cdots & \frac{\partial f_{2}}{\partial x_{n}}\left(\mathbf{p}_{k}\right) \\
\vdots & \vdots & \ddots & \vdots \\
\frac{\partial f_{n}}{\partial x_{1}}\left(\mathbf{p}_{k}\right) & \frac{\partial f_{n}}{\partial x_{2}}\left(\mathbf{p}_{k}\right) & \cdots & \frac{\partial f_{n}}{\partial x_{n}}\left(\mathbf{p}_{k}\right)
\end{array}\right]
$$

(3) Selesaikan sistem persamaan linier

$$
\mathbf{J}\left(\mathbf{p}_{k}\right) \Delta \mathbf{p}=-\mathbf{f}\left(\mathbf{p}_{k}\right) \text { untuk } \Delta \mathbf{p}
$$


(4) Hitung titik selanjutnya

$$
\mathbf{p}_{k+1}=\mathbf{p}_{k}+\Delta \mathbf{p}
$$

Ulangi proses di atas sampai $\Delta \mathbf{p}$ memenuhi batas galat yang ditentukan.

\section{Penurunan dan Langkah-langkah Metode Pseudo Arc-Length}

\subsection{Analisis Awal}

Pandang sistem

$$
\mathbf{F}(\mathbf{x}, \lambda)=\mathbf{0}
$$

dimana $\mathbf{F}: \mathbb{R}^{n+1} \rightarrow \mathbb{R}^{n}$ adalah fungsi mulus bernilai vektor. Selanjutnya misalkan himpunan solusi dari sistem (3.1) dinotasikan oleh

$$
S=\left\{(\mathbf{x}, \lambda) \in \mathbb{R}^{n+1} \mid \mathbf{F}(\mathbf{x}, \lambda)=\mathbf{0}\right\} .
$$

Dalam aplikasinya, $\mathbf{x}$ menyatakan variabel keadaan dari sistem dan $\lambda$ merupakan suatu parameter. Himpunan $S$ membentuk suatu lintasan yang dinamakan lintasan solusi. Dalam implementasi komputasi, himpunan diskrit dari titik-titik di $S$ dihitung dan kemudian dihubungkan sedemikian sehingga membentuk suatu kurva. Permasalahan utamanya sekarang adalah jika diberikan titik awal $\left(\mathbf{x}_{0}, \lambda_{0}\right) \in S$, bagaimana kemudian menghitung titik $\left(\mathbf{x}_{1}, \lambda_{1}\right)$ di $S$ yang berada di dekat $\left(\mathbf{x}_{0}, \lambda_{0}\right)$ ? Hal ini dapat dilakukan dengan memisalkan $\lambda_{1}=\lambda_{0}+\triangle \lambda$, dimana $\triangle \lambda$ bernilai kecil, lalu selesaikan $\mathbf{F}\left(\mathbf{x}, \lambda_{1}\right)=\mathbf{0}$ untuk $\mathbf{x}_{1}=\mathbf{x}\left(\lambda_{1}\right)$. Namun dengan cara ini, $\mathbf{x}\left(\lambda_{1}\right)$ bisa jadi tidak terdefinisi di sekitar titik balik. Dengan demikian perlu dikembangkan suatu metode yang dapat menghitung $\left(\mathbf{x}_{1}, \lambda_{1}\right)$ yang memutari titik balik. Metode yang dimaksud adalah metode pseudo-arclength.

\subsection{Penurunan Metode Pseudo Arc-Length}

Asumsikan bahwa himpunan $S$ hanya memiliki titik regular atau titik balik, yaitu jika $\left(\mathbf{x}_{0}, \lambda_{0}\right) \in S$, maka

$$
\operatorname{rank}\left[\mathbf{F}_{\mathbf{x}}^{0} \mid \mathbf{F}_{\lambda}^{0}\right]=n
$$

dimana $\mathbf{F}_{\mathbf{x}}^{0}$ menyatakan turunan parsial $\mathbf{F}(\mathbf{x}, \lambda)$ terhadap $\mathbf{x}$ di $\left(\mathbf{x}_{0}, \lambda_{0}\right)$ dan $\mathbf{F}_{\lambda}^{0}$ menyatakan turunan parsial $\mathbf{F}(\mathbf{x}, \lambda)$ terhadap $\lambda$ di $\left(\mathbf{x}_{0}, \lambda_{0}\right)$.

Jika $(\mathbf{x}(t), \lambda(t))$ menyatakan titik di sepanjang $S$ yang mempunyai jarak sejauh $\left(t-t_{0}\right)$ dari titik $\left(\mathbf{x}\left(t_{0}\right), \lambda\left(t_{0}\right)\right)=\left(\mathbf{x}_{0}, \lambda_{0}\right)$, maka $t$ disebut parameterisasi arc-length. Dengan demikian garis singgung terhadap $S$ di $\left(\mathbf{x}_{0}, \lambda_{0}\right)$ adalah

$$
\left[\begin{array}{l}
\frac{d \mathbf{x}}{d t} \\
\frac{d \lambda}{d t}
\end{array}\right]_{t=t_{0}}=\left[\begin{array}{c}
\dot{\mathbf{x}_{0}} \\
\dot{\lambda_{0}}
\end{array}\right]
$$

Karena $\mathbf{F}(\mathbf{x}(t), \lambda(t))=\mathbf{0}$, maka turunan terhadap $t$ menghasilkan

$$
\frac{d}{d t} \mathbf{F}(\mathbf{x}(t), \lambda(t))=\left[\mathbf{F}_{\mathbf{x}}(\mathbf{x}(t), \lambda(t)) \mid \mathbf{F}_{\lambda}(\mathbf{x}(t), \lambda(t))\right]\left[\begin{array}{c}
\dot{\mathbf{x}} \\
\dot{\lambda}
\end{array}\right]=\mathbf{0} .
$$


Pada saat $t=t_{0}$, persamaan (3.4) menjadi

$$
\left[\mathbf{F}_{\mathbf{x}}^{0} \mid \mathbf{F}_{\lambda}^{0}\right]\left[\begin{array}{c}
\dot{\mathbf{x}}_{0} \\
\dot{\lambda}_{0}
\end{array}\right]=\mathbf{0}
$$

Dengan demikian ruang vektor singgung adalah $\operatorname{ker}\left(\left[\mathbf{F}_{\mathbf{x}}^{0} \mid \mathbf{F}_{\lambda}^{0}\right]\right)$. Diketahui $\left.\operatorname{rank}\left(\mathbf{F}_{\mathbf{x}}^{0} \mid \mathbf{F}_{\lambda}^{0}\right]\right)=n$, sehingga berdasarkan Teorema $2.3, \operatorname{dim}\left(\operatorname{ker}\left[\mathbf{F}_{\mathbf{x}}^{0} \mid \mathbf{F}_{\lambda}^{0}\right]\right)=$ null $\left(\left[\mathbf{F}_{\mathbf{x}}^{0} \mid \mathbf{F}_{\lambda}^{0}\right]\right)=1$. Dengan demikian terdapat arah vektor singgung yang tunggal.

Karena $\mathbf{F}(\mathbf{x}, \lambda)=\mathbf{0}$ adalah $n$ sistem persamaan dengan $n+1$ variabel, maka solusi untuk titik baru, misalkan $\left(\mathbf{x}_{1}, \lambda_{1}\right)$ tidak dapat ditentukan secara langsung. Oleh karena itu dibutuhkan satu persamaan tambahan. Hal ini dapat dilakukan sebagai berikut.

Misalkan vektor singgung satuan dinyatakan oleh

$$
\mathbf{r}_{0}=\left[\begin{array}{l}
\mathbf{s}_{0} \\
\sigma_{0}
\end{array}\right] \in \operatorname{ker}\left[\mathbf{F}_{\mathbf{x}}^{0} \mid \mathbf{F}_{\lambda}^{0}\right]
$$

dengan $\mathbf{r}_{0}^{T} \mathbf{r}_{0}=1$. Maka titik $\left(\mathbf{x}_{1}, \lambda_{1}\right) \in S$ dapat ditentukan dengan mencari titik dimana bidang yang tegak lurus terhadap vektor singgung $\mathbf{r}_{0}$ berpotongan di $S$ (lihat Gambar 2).

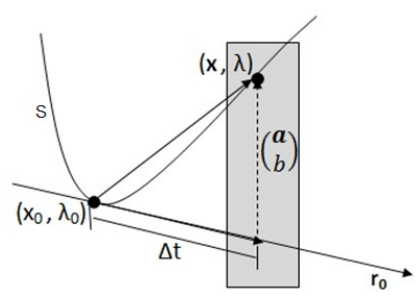

Gambar 2. Ilustrasi bidang yang tegak lurus terhadap vektor singgung $\mathbf{r}_{0}$ dan memotong $S$.

Berdasarkan hubungan vektor-vektor tersebut (lihat kembali Gambar 2), maka berlaku

$$
\left[\begin{array}{l}
\mathbf{a} \\
b
\end{array}\right]=\left[\begin{array}{c}
\mathbf{x}-\mathbf{x}_{0} \\
\lambda-\lambda_{0}
\end{array}\right]-\Delta t \mathbf{r}_{0} .
$$

Karena vektor $\mathbf{r}_{0}$ dan $[\mathbf{a} b]^{T}$ saling tegak lurus, maka

$$
\mathbf{r}_{0} \cdot\left(\left[\begin{array}{c}
\mathbf{x}-\mathbf{x}_{0} \\
\lambda-\lambda_{0}
\end{array}\right]-\Delta t \mathbf{r}_{0}\right)=0
$$

Selanjutnya diperoleh

$$
\mathbf{s}_{0}^{T}\left(\mathbf{x}-\mathbf{x}_{0}\right)+\sigma\left(\lambda-\lambda_{0}\right)-\left(t-t_{0}\right)=0
$$

yang memberikan persamaan bidang yang tegak lurus terhadap vektor singgung $\mathbf{r}_{0}$ dan memotong $S$. 
Persamaan (3.8) sekaligus merupakan persamaan tambahan pada sistem $\mathbf{F}(\mathbf{x}, \lambda)=0$, sehingga diperoleh sistem diperluas

$$
\mathbf{H}(\mathbf{y}, t)=\left[\begin{array}{c}
\mathbf{F}(\mathbf{x}, \lambda) \\
\mathbf{s}_{0}^{T}\left(\mathbf{x}-\mathbf{x}_{0}\right)+\sigma\left(\lambda-\lambda_{0}\right)-\left(t-t_{0}\right)
\end{array}\right]=\left[\begin{array}{l}
\mathbf{0} \\
0
\end{array}\right] .
$$

\subsection{Langkah-langkah Metode Pseudo Arc-Length}

Sebagai langkah pertama, tentukan terlebih dahulu solusi awal $\left(\mathbf{x}_{0}, \lambda_{0}\right)$ yang dapat diperoleh dengan menyelesaikan sistem $\mathbf{F}(\mathbf{x}, \lambda)=0$ dengan menggunakan metode Newton-Raphson. Misalkan solusi awal ini diparameterisasi pada saat $t=t_{0}$, sehingga dapat ditulis $\left(\mathbf{x}\left(t_{0}\right), \lambda\left(t_{0}\right)\right)=\left(\mathbf{x}_{0}, \lambda_{0}\right)$.

Selanjutnya tetapkan ukuran langkah $\Delta t$. Jika $t_{1}=t_{0}+\Delta t$, maka dari baris terakhir persamaan (3.9) diperoleh

$$
\mathbf{r}_{0}^{T}\left[\begin{array}{c}
\mathbf{x}_{1}-\mathbf{x}_{0} \\
\lambda_{1}-\lambda_{0}
\end{array}\right]=\Delta t
$$

dengan $\mathbf{x}_{1}=\mathbf{x}\left(t_{1}\right)$.

Lanjutkan langkah serupa untuk $t_{2}, t_{3}$ dan seterusnya, sehingga dengan menyelesaikan sistem (3.9) secara iteratif diperoleh barisan titik-titik $\left(\mathbf{x}_{2}, \lambda_{2}\right),\left(\mathbf{x}_{3}, \lambda_{3}\right)$ dan seterusnya pada $S$. Untuk memperoleh solusi $\left(\mathbf{x}_{j}, \lambda_{j}\right), j=1,2, \cdots$ yaitu dengan menentukan terlebih dahulu vektor singgung satuan $\mathbf{r}_{0}$ dengan menyelesaikan persamaan (3.5) dan kemudian hitung vektor satuannya. Untuk memudahkan perhitungan, tetapkan $\dot{\lambda}_{0}=1$, sehingga persamaan (3.5) menjadi

$$
\mathbf{F}_{\mathbf{x}}^{0} \dot{\mathbf{x}}_{0}=-\mathbf{F}_{\lambda}^{0}
$$

Dengan demikian vektor singgung $\mathbf{r}_{0}$ diberikan oleh

$$
\mathbf{r}_{0}=\left[\begin{array}{c}
\mathbf{s}_{0} \\
\sigma_{0}
\end{array}\right]=\frac{1}{\left(1+\mathbf{z}_{0}^{T} \mathbf{z}_{0}\right)^{1 / 2}}\left[\begin{array}{c}
\mathbf{z}_{0} \\
1
\end{array}\right]
$$

Selanjutnya solusi $\left(\mathbf{x}_{1}, \lambda_{1}\right)$ dapat diperoleh dengan menyelesaikan sistem diperluas (3.9) dengan menggunakan metode Newton-Raphson sebagai berikut: Tetapkan

$$
\left[\begin{array}{l}
\mathbf{x}^{(0)} \\
\lambda^{(0)}
\end{array}\right]=\left[\begin{array}{l}
\mathbf{x}_{0} \\
\lambda_{0}
\end{array}\right]
$$

maka Iterasi Newton-Raphson untuk penyelesaian sistem (3.9) diberikan oleh ,

$$
\left[\begin{array}{l}
\mathbf{x}^{(k+1)} \\
\lambda^{(k+1)}
\end{array}\right]=\left[\begin{array}{l}
\mathbf{x}^{(k)} \\
\lambda^{(k)}
\end{array}\right]+\left[\begin{array}{l}
\mathbf{d}^{(k)} \\
\delta^{(k)}
\end{array}\right]
$$

dimana $k=0,1,2, \cdots, N$ menyatakan indeks iterasi dengan jumlah maksimum ite-rasi $N$, dan

$$
\left[\begin{array}{c}
\mathbf{d}^{(k)} \\
\delta^{(k)}
\end{array}\right]=-\left[\begin{array}{cc}
\mathbf{F}_{\mathbf{x}}{ }^{(k)} & \mathbf{F}_{\lambda}{ }^{(k)} \\
\mathbf{s}_{0}{ }^{T} & \sigma_{0}
\end{array}\right]^{-1}\left[\begin{array}{c}
\mathbf{F}\left(\mathbf{x}^{(k)}, \lambda^{(k)}\right) \\
\mathbf{s}_{0}^{T}\left(\mathbf{x}^{(k)}-\mathbf{x}^{(0)}\right)+\sigma_{0}\left(\lambda^{(k)}-\lambda^{(0)}\right)-\Delta t
\end{array}\right] .
$$


Perhatikan bahwa pada iterasi pertama (untuk $k=0$ ), $\mathbf{x}^{(0)}=\mathbf{x}_{0}$ dan $\lambda^{(0)}=\lambda_{0}$ sehingga $\mathbf{F}\left(\mathbf{x}^{(0)}, \lambda^{(0)}\right)=\mathbf{F}\left(\mathbf{x}_{0}, \lambda_{0}\right)=0$. Akibatnya

$$
\left[\begin{array}{l}
\mathbf{d}^{(0)} \\
\delta^{(0)}
\end{array}\right]=\left[\begin{array}{cc}
\mathbf{F}_{\mathbf{x}^{(0)}} & \mathbf{F}_{\lambda}{ }^{(0)} \\
\mathbf{s}_{0}{ }^{T} & \sigma_{0}
\end{array}\right]^{-1} \Delta t\left[\begin{array}{l}
\mathbf{0} \\
1
\end{array}\right] .
$$

Persamaan (3.15) ekivalen dengan

$$
\left[\begin{array}{cc}
\mathbf{F}_{\mathbf{x}}{ }^{(0)} & \mathbf{F}_{\lambda}{ }^{(0)} \\
\mathbf{s}_{0}{ }^{T} & \sigma_{0}
\end{array}\right]\left[\begin{array}{c}
\mathbf{d}^{(0)} \\
\delta^{(0)}
\end{array}\right]=\Delta t\left[\begin{array}{l}
\mathbf{0} \\
1
\end{array}\right]
$$

Dengan demikian pada iterasi pertama berlaku

$$
\left[\begin{array}{c}
\mathbf{x}^{(1)} \\
\lambda^{(1)}
\end{array}\right]=\left[\begin{array}{l}
\mathbf{x}^{(0)} \\
\lambda^{(0)}
\end{array}\right]+\triangle t\left[\begin{array}{l}
\mathbf{s}_{0} \\
\sigma_{0}
\end{array}\right]
$$

Persamaan (3.17) menjelaskan bahwa $\left(\mathbf{x}^{(1)}, \lambda^{(1)}\right)$ berada di vektor singgung sejauh $\Delta t$ dari $\left(\mathrm{x}_{0}, \lambda_{0}\right)$. Selanjutnya persamaan (3.17) dapat digunakan sebagai tebakan awal pada iterasi Newton-Raphson (3.14) dalam memperoleh solusi $\left(\mathbf{x}_{1}, \lambda_{1}\right)$, artinya iterasi Newton-Raphson (3.14) dapat dihitung langsung untuk iterasi $k=1,2, \cdots, N$.

\section{Implementasi pada Matlab}

Implementasi metode pseudo arc-length pada pemrograman Matlab mengambil contoh ilustrasi dari sistem persamaan nonlinier terparameterisasi, yaitu

$$
\mathbf{F}(\mathbf{x}, \lambda)=A \mathbf{x}+\lambda e^{\mathbf{x}}=\mathbf{0},
$$

dimana

$$
A=\frac{1}{h^{2}}\left[\begin{array}{cccccc}
-2 & 1 & 0 & \cdots & \cdots & 0 \\
1 & \ddots & \ddots & \ddots & \ddots & \vdots \\
0 & \ddots & \ddots & \ddots & \ddots & \vdots \\
\vdots & \ddots & \ddots & \ddots & \ddots & 0 \\
\vdots & \ddots & \ddots & \ddots & \ddots & 1 \\
0 & \cdots & \cdots & 0 & 1 & -2
\end{array}\right]
$$

adalah matriks $n \times n$ dengan $h=\frac{1}{n}, \mathbf{x}=\left[x_{1} x_{2} \cdots x_{n}\right]^{T}$ merupakan vektor variabel dan $\lambda$ suatu parameter. Sistem (4.1) merupakan hasil diskritisasi dari persamaan Bratu yang memodelkan masalah reaksi exothermic [4], dengan menggunakan $n$ selang partisi dan lebar selang $h$.

Program Matlab menghitung nilai-nilai solusi $(\mathbf{x}, \lambda)$ yang dimulai dari $(0,0)$ dan kemudian $\|\mathbf{x}\|=\sqrt{x_{1}^{2}+x_{2}^{2}+\cdots+x_{n}^{2}}$ diplot terhadap $\lambda$. Di sini digunakan $n=50$, panjang langkah $\Delta t=\frac{1}{2}$, dan banyak langkah maksimum $M=60$.

Hasil program tersebut ditampilkan pada Gambar 3 yang menunjukkan kurva solusi dari sistem (4.1). Pada Gambar dapat dilihat bahwa kurva solusi mempunyai titik balik $(\|\mathbf{x}\|, \lambda)=(6,3.5)$. 


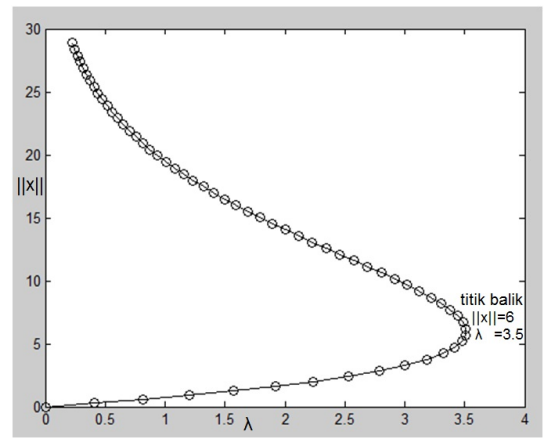

Gambar 3. Kurva solusi hasil persamaan (4.1) yang diperoleh dari metode pseudo arc-length

\section{Kesimpulan}

Pada artikel ini telah dijelaskan tentang penurunan metode pseudo arc-length dalam menyelesaikan sistem persamaan nonlinier

$$
\mathbf{F}(\mathbf{x}, \lambda)=\mathbf{0}
$$

dengan $\mathbf{x}$ menyatakan variabel dan $\lambda$ menyatakan parameter. Metode pseudo arclength ini mampu menghasilkan kurva solusi yang memiliki titik balik.

Langkah-langkah dari metode pseudo arc-length adalah sebagai berikut:

(1) Hitung solusi awal untuk titik $\left(\mathbf{x}_{0}, \lambda_{0}\right)$ dengan menyelesaikan sistem (5.1) menggunakan metode Newton-Raphson.

(2) Hitung vektor singgung satuan $\left[\mathbf{s}_{0} \tau_{0}\right]$ di titik $\left(\mathbf{x}_{0}, \lambda_{0}\right)$.

(3) Hitung solusi $\left(\mathbf{x}_{1}, \lambda_{1}\right)$ dengan menyelesaikan sistem yang diperluas

$$
\left[\begin{array}{c}
\mathbf{F}(\mathbf{x}, \lambda) \\
\mathbf{s}_{0}^{T}\left(\mathbf{x}-\mathbf{x}_{0}\right)+\sigma\left(\lambda-\lambda_{0}\right)-\left(t-t_{0}\right)
\end{array}\right]=\left[\begin{array}{l}
\mathbf{0} \\
0
\end{array}\right]
$$

dengan menggunakan metode Newton-Raphson.

(4) Lanjutkan langkah 2 dan 3 untuk memperoleh titik-titik solusi selanjutnya.

Pada artikel ini juga telah dijelaskan implementasi metode pseudo arc-length pada pemrograman Matlab dengan mengambil contoh kasus persamaan Bratu yang didiskritisasi. Dari perhitungan numerik ini diperoleh kurva solusi persamaan Bratu yang memiliki titik balik.

\section{Ucapan Terima kasih}

Penulis mengucapkan terima kasih kepada Bapak Dr. Mahdhivan Syafwan, Ibu Dr. Yanita, Ibu Dr. Susila Bahri, Bapak Zulakmal, M.Si dan Bapak Narwen, M.Si yang telah memberikan masukan dan saran sehingga artikel ini dapat diselesaikan dengan baik. 


\section{Daftar Pustaka}

[1] Anton, Howard. 1998. Aljabar Linier Elementer. Edisi kedelapan. Erlangga, Jakarta.

[2] Boyce, William E., Richard C. DiPrima. 2009. Elementary Differential Equations and Boundary Value Problems. John Wiley and Sons, New Jersey.

[3] Freitag, Melina. 2011. Nonlinear Systems and Bifurcations. $40-49$.

[4] Mathews, John H., K.D. Fink. 1999. Numerical Methods Using MATLAB. Prentice Hall, Upper Saddle River.

[5] www.wikipedia.org/Numerical Continuation, diunduh pada tanggal: 19 Maret 2015, Pukul: 19.00. 